DOI 10.21680/1517-7874.2020v22n2ID19764

\title{
A IMAGEM DO FÍSICO E SEUS ESTEREÓTIPOS UMA LEITURA DA OBRA SOLAR, DE IAN MCEWAN ${ }^{1}$
}

\section{THE IMAGE OF THE PHYSICIST AND ITS STEREOTYPES A READING OF IAN MCEWAN'S SOLAR}

\author{
Margarete Hülsendeger ${ }^{2}$ \\ Pontifícia Universidade Católica do Rio Grande do Sul (PUCRS)
}

\begin{abstract}
RESUMO
Este artigo analisa como o personagem "científico" é representado no romance Solar (2010), de Ian McEwan, examinando os elementos que indicam a presença de possíveis estereótipos. Para atingir esse objetivo, dividiu-se o texto em três partes: na primeira apresenta-se os aspectos principais da obra, destacando as "peripécias" do protagonista; na segunda examinase os conceitos de "caráter" e "tipo", as relações que existem entre eles e a forma como o físico foi representado na obra; e, na terceira, procede-se à identificação e análise de alguns dos estereótipos relacionados com a profissão de cientista.
\end{abstract}

PALAVRAS-CHAVE: Literatura; ciência; personagem; estereótipo.

\begin{abstract}
This article analyzes how the "scientific" character is represented in the novel Solar (2010), by Ian McEwan, examining the elements that indicate the presence of possible stereotypes. To achieve this objective, the text was divided into three parts: first, the main aspects of the work are presented, highlighting the "adventures" of the protagonist; second, the concepts of "character" and "type" are examined, and the relationships that exist between them and how the physicist was represented in the novel; and, the third, we proceed to the identification and analysis of some of the stereotypes related to the profession of scientist.

KEYWORDS: Literature; science; character; stereotype.
\end{abstract}

\section{INTRODUÇÃO}

Em Assunto encerrado, Italo Calvino reúne um conjunto de escritos que tratam dos mais variados assuntos - literatura, filosofia, ciência... Um desses textos é a reprodução de duas entrevistas dadas pelo autor, em 1968, reunidas sob o título: "Duas entrevistas sobre ciência e literatura" (CALVINO, 2006, p. 219). Na primeira, o escritor italiano responde à pergunta: "Em sua opinião, que relação existe hoje entre ciência e literatura?" (CALVINO, 2006, p. 219).

Segundo Calvino, existem "dois polos entre os quais oscilamos, ou pelo menos eu oscilo, sentindo atração e percebendo os limites de um e de outro" (CALVINO, 2006, p.

\footnotetext{
${ }^{1}$ Este texto tem como base uma parte da minha dissertação de mestrado (HÜLSENDEGER, 2016) em Teoria da Literatura cujo objetivo geral foi investigar como personagens originários das ciências naturais, principalmente da física, são representados na literatura. O trabalho foi realizado com apoio da Coordenação de Aperfeiçoamento de Pessoal Nível Superior - Brasil (CAPES) - Código de Financiamento 001 [This study was financed in part by the Coordenação de Aperfeiçoamento de Pessoal de Nivel Superior - Brasil (CAPES) - Finance Code 007 .

2 Professora de Física com Mestrado em Educação em Ciências e Matemática (PUCRS), Mestrado e Doutorado em Teoria da Literatura (PUCRS). Autora dos livros E todavia se move (2011) e Um diálogo improvável (2014), ambos publicados pela EDIPUCRS, nos quais são tratados, na forma de ficção, temas relacionados com a ciência. E-mail: margacenteno@gmail.com
} 
221). Um desses polos está ocupado pelas ideias defendidas por Roland Barthes, que, conforme Calvino, considerava a literatura mais científica do que a ciência, "porque a literatura sabe que a linguagem nunca é inocente, sabe que escrevendo não podemos dizer nada exterior à escritura, nenhuma verdade que não seja uma verdade condizente com o ato de escrever" (CALVINO, 2006, p. 220). No outro polo, ele coloca o escritor francês Raymond Queneau que, além de escrever, teria tido como hobby a matemática. Calvino conta que, com uma visão de ciência completamente diferente, Queneau e um amigo matemático fundaram uma espécie de agremiação - Ouvroir de Littérature Potentielle ${ }^{3}$ - onde seriam feitos experimentos e pesquisas matemático-literárias e o "divertimento, a acrobacia da inteligência e da imaginação" (CALVINO, 2006, p. 221) dominariam. Com esses dois exemplos, o escritor italiano conclui a entrevista dizendo: 'De um lado Barthes e os seus, 'adversários' da ciência, que pensam e falam com fria precisão científica; do outro lado Queneau e os seus, amigos da ciência, que pensam e falam por meio de extravagâncias e cambalhotas da linguagem e do pensamento" (CALVINO, 2006, p. 221).

Apesar de terem se passado mais de 50 anos desde a entrevista de Calvino, esse assunto "não está encerrado" e continua sendo motivo para longos debates entre os integrantes dessas duas áreas do conhecimento, situação que apenas corrobora a necessidade de mais trabalhos e pesquisas que estimulem o diálogo entre as ciências naturais e as humanidades. Nesse sentido, o primeiro passo para estabelecer uma possível relação entre ciência e literatura seja aceitar que ambas dependem da imaginação. Um cientista utiliza-se de imagens mentais tanto quanto um escritor, pois os dois sabem que lidam com elementos de uma realidade que, muitas vezes, está além dos cinco sentidos. Assim, é de se

\begin{abstract}
espantar que se exclua o processo de criação do trabalho do cientista, afinal a imaginação não é prerrogativa do artista e menosprezar o caráter imaginativo na ciência é, no mínimo, questionável. Por outro lado, na arte, fazem-se presentes os conhecimentos, métodos e visões de mundo implicados nas conquistas científicas. Artistas renascentistas, dentre os quais Leonardo Da Vinci representam bem esse fazer que se opera na convergência do inventor, matemático, físico, pintor (DAFLON, 2008, s/p).
\end{abstract}

A construção de espaços onde se finge ser o que não se é ou se age "como se fosse" real é uma das características mais importantes do trabalho de um escritor e de um cientista. Portanto, ciência e literatura têm mais pontos em comum do que se possa acreditar. Um desses pontos em comum é a presença de personagens oriundos da ciência na literatura. No teatro, têm-se A Vida de Galileu (1937-1938), de Bertolt Brecht, e Os Físicos (1962), de Friedrich Dürrenmatt. Na narrativa longa ou romance, O Dilema de Cantor (1999), de Carl Djerassi; O Caminho de Ida (2013), de Ricardo Piglia, e Aguapés (2013), de Jhumpa Lahiri.

No entanto, se quisermos saber alguma coisa a respeito dos personagens, "teremos de encarar frente a frente a construção do texto, a maneira que o autor encontrou para dar forma às suas criaturas, e aí pinçar a independência, a autonomia e a 'vida' desses seres de ficção" (BRAIT, 1985, p. 12). Passa, portanto, pela análise da estrutura do texto, e até mesmo dos conceitos compartilhados pelo autor, o entendimento de como os personagens são criados. Além disso, compreender um personagem abre a "possibilidade de adesão afetiva e intelectual do leitor, pelos mecanismos de identificações, projeção, transferência etc. A personagem vive o enredo e as ideias, e os torna vivos" (CANDIDO, 2014, p. 54).

Assim, a reflexão, por meio de personagens, pode levar a um melhor entendimento de universos que estão longe do cotidiano do leitor comum, como é o caso da ciência. Universo que pode ser experimentado quando acompanha, por exemplo, a trajetória de um personagem científico ao longo de uma narrativa literária. Se um físico, no mundo "real", é

\footnotetext{
3 A "Oulipo" (abreviatura de Ouvroir de Littérature Potentielle) tem seu site no seguinte endereço: http://www.oulipo.net/. Acesso em: 25 maio 2020.
} 
uma pessoa como qualquer outra, com defeitos, qualidades, manias, preferências, amores, ódios, tristezas e alegrias, no mundo ficcional ele não pode ser muito diferente sob pena de empobrecer-se a personalidade que está sendo criada e, consequentemente, correndo-se o risco de gerar uma obra carente de qualquer força artística de convicção (BAKHTIN, 1997). É importante, então, que o escritor saiba selecionar os traços que caracterizam o que ele acredita ser a personalidade de um cientista - em especial, de um físico - e será essa seleção que constituirá a existência desse ser fictício.

Esse movimento pode ser percebido no romance Solar (2010) do escritor inglês Ian McEwan. Nele o protagonista é um físico, ganhador do Prêmio Nobel de Física, um profissional reconhecido dentro de sua área de atuação, envolvido em diferentes projetos, uma celebridade dentro do seu círculo de trabalho. Portanto, neste artigo será analisado como o personagem "científico" é representado no romance Solar, dando-se especial atenção aos elementos que apontam para a presença de estereótipos. Para atingir esse objetivo, dividiu-se o texto em três partes: na primeira apresenta-se os aspectos principais da obra, destacando as "peripécias" do protagonista; na segunda examina-se os conceitos de "caráter" e "tipo", segundo Bakhtin, e as relações que existem entre eles e a forma como o físico foi representado na obra; e, na terceira parte, procede-se à identificação e análise de alguns dos estereótipos relacionados com a profissão de cientista, aproveitados por Ian McEwan na construção do seu protagonista.

\section{Solar: um romance bem-humorado}

A presença do macabro com algumas pitadas de humor pautam o estilo de Ian McEwan. Ele também sabe ser provocador e mordaz, com seu modo de escrever sendo descrito como preciso, racional e controlado. Já em seus primeiros trabalhos - First love, last love rites (1975), In between the sheets (1978) e The cemente garden (1978) - pode-se detectar uma escrita fascinante, repleta de imagens que são, simultaneamente, assustadoras e sensuais. Em Solar, no entanto, ele subverte essa prática optando por um humor que beira a tragicomédia.

Para conseguir esse efeito, ele criou um personagem absolutamente diferente do neurocirurgião Henry Perowne, de Saturday (2005), ou do jovem Edward, de On chesil beach (2007). O protagonista de Solar, o físico Michael Beard, é um ganhador do Prêmio Nobel, obeso, alcoólatra, mulherengo, cínico e sem nenhuma empatia. Ele vive de forma dissoluta, não tendo problemas em se apropriar das ideias dos outros ou de trair descaradamente todas as mulheres com as quais se relaciona. Empregando o discurso indireto livre - recurso que McEwan utiliza com frequência - o leitor tem acesso aos pensamentos mais íntimos de Beard, e o que encontra não é agradável, pois a mente do físico está tão povoada de imagens autoindulgentes que é quase impossível estabelecer qualquer tipo de empatia com o personagem. Para contar a história desse personagem, McEwan divide Solar em três partes, segundo os anos 2000, 2005 e 2009.

$\mathrm{Na}$ primeira parte, o autor, além de dar o tom da narrativa - mistura de humor e ironia - apresenta seu protagonista, o físico Michael Beard. Quando a história inicia, ele está com 53 anos, no quinto casamento e se define como sendo "um homem de funções limitadas, desprovido de impulsos hedônicos, monotemático, ferido" (MCEWAN, 2010, p. 11). O casamento, com sua quinta esposa Patrice, está em crise e sua carreira estagnada.

Tantas vezes infiel, agora é a sua vez de descobrir "como era complicado ser um corno. [...] Prova de que, mesmo tão tarde na vida, ele não estava imune a novas experiências" (MCEWAN, 2010, p. 12). Patrice, em represália às inúmeras traições do marido, decide também se envolver com outros homens. O primeiro é Tarpin, responsável pela reforma da casa do casal; o segundo é Aldous, um pós-graduando em física que trabalha para Beard. Estranhamente, o conhecimento da traição, em vez de afastá-lo da esposa, o torna obcecado por ela: "Na sua condição psicótica, Beard estava convencido de haver encontrado a mulher 
perfeita justamente quando se via prestes a perdê-la" (MCEWAN, 2010, p. 15). Uma obsessão cuja origem está no fato de Patrice ter se tornado uma mulher inatingível e, portanto, ainda mais desejável. Suas inúmeras trapalhadas, na tentativa de reconquistá-la, beiram ao ridículo e são, na maior parte do tempo, muito engraçadas. Mais tarde, quando decidem se separar, eles assumem uma amizade civilizada e a distância. Essa é uma característica interessante do personagem, apesar dos vários casamentos e casos extraconjugais, ele sempre consegue manter uma boa relação com suas antigas esposas e amantes: "Ele gostava de pensar que, se houvesse causado alguma infelicidade, nunca fora por muito tempo, não sendo à toa que mantinha um relacionamento amigável com todas as quatro" (MCEWAN, 2010, p. 12).

Quando a segunda parte começa o ano é 2005 e Beard, agora com 58 anos, está completamente envolvido com o projeto que "roubou" do seu ex-funcionário, o estudante de pós-graduação e amante de sua quinta mulher, Tom Aldous. Beard encontra no americano Tom Hammer, o parceiro ideal para levar adiante o plano de extrair energia a partir da fotossíntese das plantas. O fato de ter roubado a ideia de um colega não o incomoda, pois foi ele que "compreendeu como ninguém o verdadeiro valor do trabalho de Tom, que por sua vez se baseava no de Beard, assim como o dele se baseava no de Einstein" (MCEWAN, 2010, p. 226). Para atingir seus objetivos (enriquecer e conquistar reconhecimento e prestígio), Beard passa a desejar que o aquecimento global seja algo inevitável. A possibilidade de um apocalipse não o assusta, talvez porque acredite que não estará mais vivo para presenciá-lo, não podendo afetá-lo. McEwan, na segunda parte do livro, consolida as características do seu protagonista e em momento algum são dadas esperanças ao leitor de que algum tipo de redenção possa ocorrer. Como aconteceu no final da primeira parte, aqui também Beard vê a sua vida passar por um ponto de inflexão: a perspectiva de ser pai. Contudo, como é normal em sua conduta, ele prefere fingir uma normalidade que está longe de existir. Ele parece acreditar que as situações se arranjam naturalmente, não havendo necessidade de empenhar-se no sentido de mudar seu comportamento diante da vida. Beard vive em uma espécie de cegueira autoinduzida que desafia qualquer tipo de racionalidade.

Mais quatro anos se passam, agora é 2009, terceira e última parte de Solar. Beard encontra-se convenientemente estabelecido em sua vida, tentando (sem muito sucesso) ser um pai para a filha de três anos. No entanto, o caos permanece sendo uma constante na sua vida; Beard, agora com 62 anos, segue bebendo e comendo descontroladamente. De uma maneira um tanto freudiana, o narrador procura justificar alguns dos aspectos da personalidade de Beard lançando uma luz sobre sua origem familiar: "Sua mãe, Angela, era uma bela mulher de formas angulosas que o paparicava usando a comida para transmitir o amor que sentia por ele" (MCEWAN, 2010, p. 233). Além disso, em seu leito de morte, a mãe confessa ter tido inúmeros casos - 17 em 11 anos - alegando que se não fosse por eles teria enlouquecido. O pai, por outro lado, é um homem calmo e muito magro, mas, apesar de ser dedicado à família, tinha enormes dificuldades em demonstrar qualquer tipo de afeto ou carinho. Com essas informações, sobre a infância e adolescência de Beard, McEwan parece querer justificar a alienação do personagem, já que o físico reconhece nunca ter suspeitado dos problemas vividos por seus pais e nem das infidelidades da mãe até que ela mesma as confessasse em seu leito de morte.

A última frase do livro revela o estilo característico de McEwan, não dar um final fechado a suas histórias: "Quando se levantou a fim de recebê-la, Beard sentiu algo estranho, o coração se dilatando, mas, ao abrir os braços para ela, duvidou que alguém jamais acreditaria se tentasse agora chamar aquilo de amor" (MCEWAN, 2010, p. 332). Uma frase que, se por um lado, consolida aquilo que o leitor já esperava - um final "cataclísmico" para Beard -, por outro, deixa uma série de dúvidas, sobre o que realmente aconteceu com o personagem. A expressão "coração se dilatando", faz o leitor se questionar se Beard está diante de um enfarte fulminante ou se nessa hora de desespero, quando percebe ter perdido tudo, seu coração, enfim, consegue, não só reconhecer, mas principalmente, sentir uma emoção tão 
forte como o amor. A resposta o leitor não irá encontrar no final do livro, restando-lhe apenas aceitar os diferentes fins possíveis para o protagonista de Solar, o físico Michael Beard.

\section{2 "Caráter" e "tipo" reunidos na representação de Michael Beard}

Bakhtin, ao caracterizar a relação entre personagem e autor, estabelece a diferença entre "caráter" e "tipo". Para ele, quando o primeiro está presente, o herói é apresentado de maneira que "todas as coisas têm por função caracterizá-lo" e tudo se resume a formular e responder à pergunta, "quem é ele" (BAKHTIN, 1997, p. 187). O "tipo", além de estar "profundamente entrelaçado com o mundo material que o rodeia" (BAKHTIN, 1997, p. 197), é também condicionado por esse mundo. Assim, enquanto o "caráter" é plástico, o "tipo" é pitoresco.

Na construção clássica do "caráter", Bakhtin considera que a determinação de um "destino" é fundamental porque o "herói" age como deve agir por ser o correto, por ser o necessário, por ter vontade (BAKHTIN, 1997). O autor olha seu personagem como se estivesse vendo-o pelo lado de fora "lançando mão de todos os privilégios da sua exotopia completa em relação ao herói” (BAKHTIN, 1997, p. 188). Essa "determinação do destino" pode ser percebida nas diversas reflexões feitas pelo físico Michael Beard ao longo da narrativa. Em relação ao sexo, ele questiona-se: "Será que seu apetite por uma mulher tão volumosa era uma forma de amar a si próprio?" (MCEWAN, 2010, p. 317). Do mesmo modo, quando avalia seu espaço físico privado, percebe que seu apartamento reflete "algum aspecto de si próprio, aquilo que tinha de pior, de mais obeso, a incapacidade de traduzir num curso de ação qualquer plano razoável” (MCEWAN, 2010, p. 268). Beard constrói sua vida (pensa, sente e age) em função dos objetivos que ele mesmo traçou, realizando os significados do objeto e do sentido pelos quais orienta a sua existência (BAKHTIN, 1997).

Esse conceito determinista fica ainda mais evidente quando o narrador de Solar, no início da segunda parte do livro, comenta: "Ninguém se surpreendia ao ser informado de que Michael Beard era filho único, e ele seria o primeiro a concordar que nunca aprendera o que era um sentimento fraternal" (MCEWAN, 2010, p. 233). A ausência da surpresa, mencionada pelo narrador, vem do que Bakhtin chamou de "já-aqui existencial”, ou seja, o personagem tem origens (pai e mãe) impossíveis de negar, pois mesmo que elas não lhe pertençam - ou não lhes dê valor -, ele, em algum nível, pertence a elas. Esse conceito de pertença aparece, por exemplo, na reflexão de Beard sobre a sua adolescência, quando lembra que se "sentia ignorante, incompetente e infeliz, enquanto todo mundo misteriosamente sabia de tudo e parecia estar em conluio contra ele" (MCEWAN, 2010, p. 70). Uma memória que, no tempo presente, apenas aumenta sua indecisão e falta de jeito.

Conforme a história se desenvolve, a sensação de um fim inevitável fica cada vez mais evidente. $\mathrm{O}$ autor, ao jogar com a ideia de que tudo está determinado, justifica as atitudes recorrentes do personagem, afinal ele "age assim por que é assim" (BAKHTIN, 1997, p. 190, grifos do autor). Não há, portanto, qualquer possibilidade de redenção. Até mesmo a culpa quando aparece não é uma culpa moral, já que "o herói poderia ter cometido a falta sem suspeitar do significado do que era cometido" (BAKHTIN, 1997, p. 191). Dessa forma, a dificuldade de estabelecer uma relação com a filha de três anos não é para Beard motivo de ansiedade ou preocupação. $\mathrm{Na}$ verdade, trata-se de um comportamento de tal forma enraizado, que ele não vê nenhuma necessidade de mudar sua maneira de ser, como se verifica na comparação que ele estabelece entre as conversas com a filha e as que manteve com as várias mulheres de sua vida:

\footnotetext{
Muitas conversas com sua filha de três anos o faziam lembrar-se das trocas ao longo dos anos com várias mulheres a quem se explicara de forma implausível, ou voltara atrás no que dissera, ou apelara para desculpas esfarrapadas — sem nunca enganar nenhuma delas (MCEWAN, 2010, p. 263).
} 
O caráter com o qual Ian McEwan dota seu personagem tem todas as particularidades enunciadas por Bakhtin: o herói é dado no seu todo, presença da casualidade determinando suas ações, uma individualidade muito forte e a culpa inerente ao seu destino sendo "transposta para fora dos limites da consciência e do conhecimento do herói" (BAKHTIN, 1997, p. 191). O escritor Orhan Pamuk lembra, no entanto, que o conceito de caráter durante anos fez a comunidade literária e a crítica mundial esquecer "que o que chamamos de 'caráter' era, sobretudo no romance, fruto da imaginação humana, um constructo artificial” (PAMUK, 2011, p. 51). Nesse sentido, na representação de Michael Beard, além dos traços de seu caráter, há uma consciência moldada pelas situações que o autor criou intencionalmente ao longo da narrativa.

Segundo Compagnon:

A intenção do autor que escreveu uma obra é logicamente equivalente àquilo que ele queria dizer pelos enunciados que constituem o texto. E seus projetos, suas motivações, a coerência do texto para uma dada interpretação são, afinal de contas, indicadores dessa intenção (COMPAGNON, 2010, p. 91).

Se levarmos em conta os indicadores presentes em Solar, é possível inferir que a intenção de Ian McEwan foi utilizar um misto de humor e ironia para escrever sobre um assunto sério: as mudanças climáticas e sua relação com o aquecimento global. Há, como na maioria de suas obras, uma tensão narrativa, só que em Solar trata-se de uma tensão cômica. Portanto, mesmo que o protagonista tenha muitos de seus traços determinados por um "caráter" no qual o destino é uma peça essencial, ele também é um "tipo pitoresco" nas suas ações e pensamentos.

Esse sentido do "pitoresco", ou do divertido, transforma a história em uma sátira na qual o elemento central é o homem de ciência, aqui representado por Beard. Italo Calvino explica que apesar de a sátira excluir uma postura de interrogação, de busca, ela não exclui "uma parte forte de ambivalência, isto é, a mistura de atração e repulsa que anima qualquer satírico verdadeiro com relação ao objeto de sua sátira" (CALVINO, 2006, p. 188). Essa ambivalência apontada por Calvino aparece na forma como os vícios e imperfeições do protagonista são realçados pelo autor, convertendo-o no que Bakhtin denominou de "tipo injurioso", ou seja, alguém que "procura na existência o cunho exagerado e ultrajante daquilo que é transcendente ao homem em sua vida" (BAKHTIN, 1997, p. 197). Esse exagero, do qual Bakhtin fala, aparece em vários momentos da narrativa, expondo as fraquezas do protagonista ao escrutínio do leitor.

Um dos pontos altos da vida de Michael Beard é a sua relação com as mulheres. Como ele rejeita qualquer forma de vínculo emocional, as cenas de sexo, apesar de serem destituídas de qualquer conteúdo erótico, são uma fonte de informações sobre o mundo mental do personagem:

\footnotetext{
Apenas dez anos antes, quando ainda imaginava poder se salvar por meio de exercícios, ele teria se chocado com seu formato pneumático e o acordeão de queixos, assim como com os contornos adiposos da mulher que acariciava e com o cheiro suarento de grama recém-cortada que vinha das axilas, virilhas e das partes de trás dos joelhos dela, áreas densamente dobradas que só de raro em raro entravam em contato com o ar ou a luz. E, no entanto, tudo era tão excitante quanto sempre fora (MCEWAN, 2010, p. 314).
}

A imagem ofensiva de si mesmo reflete-se na imagem da amante e, nessa relação, Beard encontra um prazer que nem mesmo ele sabe explicar. O personagem não está apenas preso ao mundo material que o rodeia, mas também está condicionado por ele. Beard, na maior parte do tempo, aparenta não ter consciência do que suas palavras e ações podem 
provocar, e é essa ignorância, muitas vezes levada ao extremo, que carrega a narrativa de uma comicidade onde o riso tem um espaço garantido.

Para Bakhtin, o riso é uma

posição estética determinada diante da realidade, mas intraduzível à linguagem da lógica, isto é, é um determinado método de visão artística e interpretação da realidade e, consequentemente, um método determinado de construção da imagem artística, do sujeito e do gênero (BAKHTIN, 1981, p. 142).

No caso de Solar, está se tratando com o "riso carnavalesco ambivalente", um riso que possui uma enorme força criativa e no qual está entrelaçada "inseparavelmente a ridicularização e o júbilo, o elogio e o impropério" (BAKHTIN, 1981, p. 142). Quando a imagem do "riso carnavalesco" é transposta para a literatura, é possível ao autor transformála de acordo com a intenção da obra, permitindo "ver e mostrar momentos do caráter e do comportamento das pessoas que não poderiam revelar-se no curso normal da vida" (BAKHTIN, 1981, p. 142). O cômico converte-se no caminho de saída dos limites e da uniformidade de toda a representação e de todo o julgamento porque

podemos dizer uma coisa ao menos de duas maneiras: a maneira como quem a diz quer dizer aquela coisa e somente ela; e uma maneira como queremos dizer, sim, aquela coisa mas ao mesmo tempo recordar que o mundo é muito mais complicado e vasto e contraditório (CALVINO, 2006, p. 189).

Esse processo pode ser percebido nas várias cenas que descrevem a viagem de Michael Beard ao Polo Norte. A comicidade está presente desde a sua chegada à estação, atrasado por não saber vestir as roupas apropriadas, passando pela vontade de urinar em um ambiente onde a temperatura era vinte e seis graus abaixo de zero, até ter o pênis preso no fecho da roupa:

[...] terminada a função, ele descobriu que seu pênis se colara ao zíper da roupa externa, congelando-se ao longo da extensão do fecho ecler como a carne sói fazer em contato com um metal em temperaturas inferiores a zero. Desperdiçou preciosos segundos contemplando, em choque, a situação. Quando por fim deu uma puxadinha tentativa, sentiu uma dor terrível. E vale notar que já sentia bastante dor por causa do frio (MCEWAN, 2010, p. 76-77).

A construção cômica dessas cenas ajuda a revelar muitas das características que constituem a personalidade de Michael Beard, mas, ao mesmo tempo, o tipificam como um personagem moldado às circunstâncias de um certo ambiente. Trata-se de um indivíduo, não só insensível às preocupações dos outros, mas completamente ignorante ao caos que é capaz de provocar à sua volta. Um caos que atinge pessoas e espaços físicos de igual maneira, como McEwan faz questão de descrever no episódio da "sala das botas":

O estado da sala das botas, a crescente entropia, se tornou um assunto presente em todos os anúncios feitos por Barry Pickett no fim do dia. E Beard, ignorando sua própria contribuição vital, sua generosa assistência no estabelecimento das condições iniciais, não podia deixar de refletir longamente sobre aquela degeneração “após a Queda” (MCEWAN, 2010, p. 99, grifos meus).

A narrativa enriquecida com o acréscimo de expressões vindas da física (entropia, por exemplo), torna-se uma forma de lembrar ao leitor que não se trata de um personagem comum, mas de um "capitalista científico" (BOURDIEU, 2004), ou seja, um homem cujo "capital" repousa sobre o reconhecimento de uma "competência que, para além dos efeitos que ela produz e em parte mediante esses efeitos, proporciona autoridade e contribui para 
definir não somente as regras do jogo, mas também suas regularidades (BOURDIEU, 2004, p. 27). O conhecimento de que se trata de alguém "qualificado", uma autoridade na sua área, capaz de explicar de "maneira científica" qualquer tipo de situação na qual esteja envolvido faz com que a cena se torne ainda mais cômica. Desse modo, o físico respeitado, Prêmio Nobel, transforma-se por motivos diversos - alguns sendo o resultado de um determinismo exagerado - em um indivíduo sem escrúpulos, indiferente às necessidades do outro. Porém, é essa "ignorância emocional" e os excessos (alimentares, etílicos e sexuais) sobre os quais ele, aparentemente, não tem (ou não quer ter) controle que o tornam divertido, quase caricato.

Esses elementos, combinados pelo autor, resultam em um personagem complexo que reúne traços que procuram representar a vida - uma vida inventada - da maneira mais acurada possível. Logo, não deve espantar que o personagem "pareça o que há de mais vivo no romance; e que a leitura deste dependa basicamente da aceitação da verdade da personagem por parte do leitor" (CANDIDO, 2014, p. 54, grifos do autor). No caso do protagonista de Solar, essa "aceitação da verdade" passa por perceber que muitos dos traços escolhidos por Ian McEwan podem ter tido inspiração em estereótipos associados à figura do homem de ciência, os quais, frequentemente, reforçam a ideia de que um cientista costuma agir de maneira excêntrica, muitas vezes, ignorando suas responsabilidades sociais. A identificação e análise dos estereótipos utilizados pelo autor para construir seu protagonista será o tema abordado a seguir.

\section{A presença de estereótipos na construção de Michael Beard}

Para Roland Barthes, “o estereótipo é a palavra repetida, fora de toda magia, de todo entusiasmo [...]: palavra sem cerimônia, que pretende a consistência e ignora sua própria insistência" (BARTHES, 2013, p. 52). Homi Bhabha explica que o estereótipo se trata de "uma forma de conhecimento e identificação que vacila entre o que está sempre 'no lugar', já conhecido, e algo que deve ser ansiosamente repetido" (BHABHA, 1998, p. 105). Já Pereira considera que os estereótipos

não devem ser necessariamente definidos como exageros na concepção sobre o que um grupo é (embora eles tipicamente sejam), nem como generalizações sobre a prevalência dos atributos estereotipados nos membros do grupo alvo (embora eles também tipicamente sejam) e nem precisam ser amplamente compartilhados (embora eles uma vez mais, tipicamente sejam) (PEREIRA, 2002, p. 45).

Nesse sentido, o escritor, astrofísico e cosmólogo Carl Sagan considera a atividade de cientista como uma das profissões mais estereotipadas. Em seu livro O mundo assombrado pelos demônios (1995), ele diz que os cientistas são considerados nerds socialmente inoportunos que trabalham com temas incompreensíveis para as pessoas normais (SAGAN, 2006). Para provar essa ideia, Sagan pediu a uma especialista em crianças de onze anos que fizesse com seus alunos uma caracterização "esquemática e contemporânea dos nerds da ciência" (SAGAN, 2006, p. 428). O resultado dessa pesquisa gerou um conjunto de imagens que com frequência podem ser encontradas, não só na literatura, mas também no cinema:

\footnotetext{
Os nerds usam cintos logo abaixo das costelas. As suas camisas de mangas curtas são equipadas com protetores de bolso que exibem um conjunto formidável de canetas e lápis coloridos. [...] Todos eles usam óculos de lentes grossas com armações quebradas em cima do nariz que foram consertadas com band-aids. São destituídos de talentos sociais, fato de que se esquecem ou de que não fazem caso. [...] Conversam uns com os outros numa língua incompreensível. [...] Desprezam as pessoas normais, que por sua vez riem deles. [...] Eles não têm encontros amorosos (SAGAN, 2006, p. 428-429).
} 
As ideias dessas crianças sobre a figura do cientista não são muito diferentes das observadas em adultos, como comprovam estudos sobre esse tema (KOSMINSKY; GIORDAN (2002); OLIVEIRA (2006); GALLEGO-TORRES (2007); CUNHA; GIORDAN (2009)). Outra referência sobre o mesmo assunto é o livro From faust to strangelove (1994), da bioquímica e escritora australiana Roslynn Haynes. Nele, a autora apresenta alguns dos estereótipos recorrentes na literatura ocidental: (1) o cientista diabólico movido por objetivos intelectuais secretos com inspiração ideologicamente maléfica; (2) o professor bem intencionado, mas ingênuo, preocupado apenas com as trivialidades de seu mundo científico privado; (3) o herói aventureiro, que se arrisca a qualquer perigo, explorando novos territórios ou novos conceitos; (4) o idealista ou salvador da humanidade, sempre envolvido em conflitos com o sistema tecnológico que não respeita valores humanos; e (5) o cientista como inventor genial (HAYNES, 1994). Na leitura de Solar é possível observar a presença de alguns desses estereótipos "clássicos" relacionados a figura do homem de ciência.

Michael Beard, ao longo de toda narrativa, demonstra uma inegável dificuldade de se relacionar satisfatoriamente com as pessoas à sua volta. Isso transparece na sua relação com as mulheres, com a filha, com os colegas de trabalho e com qualquer grupo com o qual ele tente interagir. Contudo, em momento algum ele demonstra ansiedade ou desejo de alterar essa situação. Na verdade, ele sente prazer, e até orgulho, em se considerar um misantropo:

\footnotetext{
Agora que a estava beijando, se deu conta de que deveria ter tido saudade, porque estava excitado e feliz. Mas não tinha sentido a falta de ninguém desde o tenebroso verão de 2000, quando teve um desejo de cão por sua última, sua derradeira mulher. Havia pessoas que vagamente tinha vontade de ver, porém desde aquela época não voltara a ser afligido por nenhuma ausência. Ultimamente, tão $\operatorname{logo}$ se encontrava a sós, ele lia, bebia, comia, falava no telefone, acessava a internet, via televisão, viajava para os encontros (MCEWAN, 2010, p. 205, grifos meus).
}

O personagem é, portanto, um misantropo assumido e sua aversão às pessoas aparece em diferentes momentos da narrativa: (1) quando se vê confinado com mais vinte pessoas em uma estação de estudos no Polo Norte; (2) na fila de desembarque do aeroporto de Londres - "Em momentos como aquele, sua misantropia o tornava mais sensível às pessoas apinhadas ao seu redor, não mais companheiros de viagem, e sim adversários, competidores numa corrida lenta" (MCEWAN, 2010, p. 138) -; e (3) até mesmo quando está com uma de suas mulheres - "Dez minutos antes sentira que pertencia a ela. Agora, a ideia de pertencer a qualquer pessoa, de que qualquer pessoa pudesse pertencer a outra, era sufocante" (MCEWAN, 2010, p. 315). A misantropia de Beard oscila ao sabor das circunstâncias a ponto de, em determinados momentos da história, ele tornar-se um pouco melancólico, acreditando que, se viajasse para outra galáxia, "logo sentiria uma falta mortal daqueles irmãos e irmãs à sua frente, de todo mundo, até mesmo das ex-mulheres" (MCEWAN, 2010, p. 101). O autor, no entanto, não permite que esse estado de espírito se estenda por muito tempo e interrompe a fantasia de Beard, declarando que ele fora invadido pela doce ilusão de que gostava das pessoas, pois são "perfeitamente desculpáveis, todas elas. Um pouco cooperativas, um pouco egoístas, às vezes cruéis e, acima de tudo, engraçadas" (MCEWAN, 2010, p. 101).

Outro estereótipo sobre o cientista explorado por McEwan refere-se ao "visual nerd'. Através dos olhos de Maisie Farmer, futura primeira esposa de Beard, o leitor tem a oportunidade de "ver" qual a aparência do personagem quando era um jovem estudante de física:

Um sujeito gorducho com cara de contador e jeitão sério, usando gravata (em 1967!), cabelos curtos repartidos no lado e — detalhe abominável — uma caneta 
espetada no bolso da frente do paletó. E estudava ciência, uma bobageira que só interessava a alguns idiotas (MCEWAN, 2010, p. 239).

Nesse parágrafo, evidencia-se não só a questão envolvendo a maneira de vestir, mas o fato de um nerd conversar sobre assuntos que ninguém entende e nem tem interesse em entender. Porém, o protagonista de McEwan apesar de parecer um nerd, não aceita essa imagem como um fato consumado, preferindo a companhia dos "engenheiros, que lhe davam acesso às oficinas, além dos geógrafos, zoólogos e antropólogos, em especial os que já haviam feito trabalhos de campo em lugares exóticos" (MCEWAN, 2010, p. 237-238), a de seus colegas de curso, estudantes de matemática e física, por considerá-los muito introvertidos e tímidos.

Beard começa a abandonar esse espaço estereotipado do "nerd cientista" quando encontra Maisie. A perseguição, implacável e muito bem organizada, empreendida para conquistar aquela que seria a sua primeira esposa permite que o leitor acompanhe a transformação de Beard de um estudante nerd em alguém (segundo o ponto de vista do personagem) mais interessante e "sofisticado". A mudança começa pela roupa - "Ela o persuadiu a deixar o cabelo crescer, a usar jeans em vez de calças de flanela, a parar de consertar coisas. Não caía bem" (MCEWAN, 2010, p. 244) - e segue para as amizades - "Os amigos dela, estudantes de literatura e história, passaram a ser dele também. Eram mais engraçados que seus outros amigos, e naturalmente mais indolentes, sedentos de prazer, como se tivessem direito a isso" (MCEWAN, 2010, p. 244).

Ian McEwan joga com todos esses estereótipos, aparentemente sugerindo que estereotipar faz parte da natureza humana. Assim, quando Beard diz suspeitar "não haver nada que eles discutissem que não pudesse ser compreendido por qualquer pessoa de inteligência modesta" (MCEWAN, 2010, p. 243), fica claro que ele também tem uma imagem distorcida dos "estudantes de humanidades" e que o ato de estereotipar além de alimentar a culpa e a agressividade, mascara a cisão dos saberes oficiais (BHABHA, 1998). Essa cisão aparece em vários trechos da narrativa. Em um deles, Beard declara-se "intelectualmente livre" porque percebe que enquanto

\begin{abstract}
ele e seus colegas assistiam a aulas e faziam trabalhos de laboratório das noves às cinco diariamente, tentando destrinchar algumas das coisas mais complexas que haviam sido pensadas até então. Os estudantes de humanidades caíam da cama ao meio dia para assistir às duas aulas da semana. Beard suspeitava não haver nada que eles discutissem que não pudesse ser compreendido por qualquer pessoa de inteligência modesta (MCEWAN, 2010, p. 243).
\end{abstract}

Esse sentimento de superioridade é mais um dos estereótipos abordados por McEwan. Beard acredita ser o único a conseguir "ver" claramente em meio a uma população de cegos e ignorantes: "Fizeram-lhe perguntas respeitosas, que ele respondeu sensatamente, lucidamente. Estava cercado de analfabetos científicos e poderia ter dito qualquer coisa" (MCEWAN, 2010, p. 95). A falta de autocrítica e de humildade do personagem permite que o autor "dispare" contra diferentes alvos. Assim, utilizando a voz de Beard, disfarçada sempre em um discurso indireto-livre, o narrador "atira" contra (1) a publicidade - "a publicidade era um campo para medíocres" (MCEWAN, 2010, p. 136) - (2) a imprensa - "a cobertura de imprensa havia feito seu truque de criar nas pessoas uma fome, o desejo de verem um monstro moderno em carne e osso e se horrorizarem" (MCEWAN, 2010, p. 167) - (3) a pósmodernidade - "ali estava um pessoal pós-moderno, com antenas bem treinadas para captar qualquer frase inaceitável” (MCEWAN, 2010, p. 169) - e (4) até contra as narrativas literárias - "Gente fixada na narrativa costumava ter uma visão estranha da realidade, acreditando que todas as versões dela tinham igual valor" (MCEWAN, 2010, p. 179). O interessante é que, no contexto da obra, todas essas declarações acabam se constituindo em uma complexa relação entre o autor, o narrador, o personagem e o texto. 
Para Orhan Pamuk, a leitura de romances é sempre colorida pela incerteza resultante de um jogo de espelhos, onde não se consegue determinar que parte da história se baseia na experiência e que parte é fruto da imaginação (PAMUK, 2011). Já Antonio Candido acredita que a ficção é "o único lugar - em termos epistemológicos - em que os seres humanos se tornam transparentes à nossa visão, por se tratar de seres puramente intencionais sem referência a seres autônomos; de seres projetados por orações" (CANDIDO, 2014, p. 35). O conceito defendido por Antonio Candido confirma a ideia de que não era a intenção de Ian McEwan simplesmente transformar Michael Beard em um avatar de algum cientista famoso ou dele mesmo. Contudo, na escolha dos traços da personalidade de Beard, é possível perceber essa linha fina entre imaginação e realidade apontada por Pamuk, pois algumas das características pessoais de personalidades conhecidas da ciência (Albert Einstein, Paul Dirac) e, talvez, do próprio autor, estão presentes na composição do personagem, dando-lhe coerência, consistência e verossimilitude. De qualquer forma, a presença de estereótipos, no caso de Solar, contribuiu na caracterização do personagem, enriquecendo a história e dando um toque de humor facilmente perceptível.

\section{CONSIDERAÇÕES FINAIS}

Estabelecer os limites entre uma reprodução fiel da realidade e a simulação do real não é uma tarefa fácil, já que "a noção a respeito de um ser, elaborada por outro ser, é sempre incompleta, em relação à percepção física inicial. E que o conhecimento dos seres é fragmentário" (CANDIDO, 2014, p. 56). Exige do escritor o que Bakhtin chamou de "objetividade estética" (BAKHTIN, 1997, p. 212), algo que tem relação com a realidade do herói. Segundo ele, essa realidade difere da realidade das ciências naturais, pois se relaciona não com uma realidade cognitiva ou prático-empírica, mas com uma "realidade do acontecer" (BAKHTIN, 1997, p. 213). Portanto, não se trata de uma dinâmica física, mas do acontecimento criado pelo autor, e é por ela que se avalia a verossimilhança artística, a objetividade estética e a fidelidade (BAKHTIN, 1997). Da mesma forma, o "funcionamento das personagens, depende dum critério estético de organização interna. Se esta funciona, aceitaremos inclusive o que é inverossímil em face das concepções correntes" (CANDIDO, 2014, p. 77, grifo do autor).

O "caráter" de Michael Beard segue a correlação entre o autor e o herói, este concebido como uma pessoa determinada e na qual todas as informações têm o objetivo de caracterizá-la: ele "age assim por que é assim" (BAKHTIN, 1997, p. 190, grifos do autor). Tratase, portanto, de uma visão determinista que justifica as ações do personagem, a ponto de a culpa ser transposta para fora da sua consciência e do seu conhecimento. Além disso, o destino, como forma de determinação total do indivíduo, é uma marca importante na representação de Michael Beard, porque o leitor descobre, no decorrer da leitura, que não pode esperar mudanças na forma como personagem vê o mundo e a vida ficcional passa a ser somente a realização daquilo que, desde o início, se encontrava na determinação de sua existência (BAKHTIN, 1997).

Por outro lado, também é possível observar na representação do protagonista de Solar elementos que o caracterizam como um "tipo", permitindo ao autor separar-se "totalmente do mundo a que pertence o herói”" (BAKHTIN, 1997, p. 197). Como a sátira, o humor e, por consequência, o riso estão presentes na narrativa. A afronta, o exagero e o ridículo são fatores que influenciam diretamente na construção da comicidade que atravessa toda a obra, pois, enquanto o "ambiente do caráter recebe certa simbolização, o mundo material que rodeia o tipo se parece com um inventário” (BAKHTIN, 1997, p. 196). Dessa maneira, o tipo passa a representar a "posição passiva de uma pessoa coletiva" (BAKHTIN, 1997, p. 196, grifo do autor) que, no interior da narrativa de Solar, pode ser reconhecida pelas imagens estereotipadas empregadas pelo autor com o objetivo de provocar um "efeito de 
verdade probabilística e predictabilidade que, para o estereótipo, deve sempre estar em excesso do que pode ser provado empiricamente ou explicado logicamente" (BHABHA, 1998, p. 106).

Um dos estereótipos mais comuns no que se refere à representação do cientista é vê-lo como um indivíduo insensível, alheio às relações humanas, capaz de suprimir todas as ligações afetivas pela causa da ciência. Esse estereótipo, assim como tantos outros,

não é uma simplificação porque é uma falsa representação de uma dada realidade. É uma simplificação porque é uma forma presa, fixa, de representação que, ao negar o jogo da diferença (que a negação através do Outro permite), constitui um problema para a representação do sujeito em significações de relações psíquicas e sociais (BHABHA, 1998, p. 117).

Em Solar, o uso de estereótipos relacionados com o cientista demonstra que o autor, ao construir seu personagem, levou em consideração diversos elementos - aparência física, comportamento e aspectos da intimidade - que reforçam a imagem do homem de ciência, em especial dos físicos, como indivíduos excêntricos, arrogantes, centrados neles mesmos ou no trabalho que estão realizando e, como consequência, seres alienados. Carl Sagan procura justificar esse comportamento antissocial do "nerd cientista" dizendo que

talvez as pessoas que não têm talento para o convívio social encontrem refúgio em investigações impessoais, particularmente na matemática e nas ciências físicas. Talvez o estudo sério de temas difíceis requeira tanto trabalho e dedicação que sobra muito pouco tempo para aprender algo além das cortesias sociais mais simples (SAGAN, 2006, p. 429).

No caso de Michael Beard, essa explicação pode se aplicar, mas apenas em parte. O personagem, realmente, é inconsciente de suas trapalhadas e, por conta delas, comporta-se de forma inadequada. Contudo, não se tratam de atitudes inocentes ou destituídas de malícia. Quando rouba a pesquisa de seu colega morto Beard não age por impulso, mas de forma premeditada, utilizando artifícios supostamente racionais para justificar suas ações. Do mesmo modo, quando afirma não gostar das pessoas, contraria essa afirmativa ao demonstrar que precisa estar constantemente rodeado delas, sendo reconhecido e valorizado.

Os estereótipos incluídos pelo autor, além de enfatizar os aspectos principais de sua personalidade, fazem um contraponto no que se refere à imagem romântica do cientista: um indivíduo desinteressado, pensando apenas nos assuntos "científicos", apartado do mundo, incapaz de gerir seu trabalho de pesquisa por estar submetido a forças que o manipulam. Todas essas representações

valorizam o imaginário como instância da realidade, se conformam com a indeterminação e fragmentação da realidade, com a ausência de um referente para as representações do conhecimento, com a carência de uma visão de totalidade e com o caráter limitado (não absoluto) das interpretações (OLIVEIRA, 2006, p. 140).

Nesse conjunto de imagens estereotipadas criadas pelo autor, não são esquecidos nem mesmo os preconceitos que existem entre os diferentes campos do conhecimento. Com humor, Ian McEwan expõe as opiniões dos integrantes das áreas das ciências naturais ("exatas" ou "duras") sobre seus colegas das humanidades (e vice-versa), reforçando a ideia de que a vida intelectual da sociedade ocidental estaria dividida em dois grupos: a dos literatos e a dos cientistas. Entre esses dois grupos existiria um

abismo de incompreensão mútua - algumas vezes (particularmente entre os jovens) hostilidade e aversão, mas principalmente falta de compreensão. Cada um 
tem uma imagem curiosamente distorcida do outro. Suas atitudes são tão diferentes que, mesmo ao nível da emoção, não encontram muito terreno comum (SNOW, 2015, p. 21).

Assim, enquanto os literatos tendem a pensar que os cientistas são impetuosos, orgulhosos e incapazes de entender a situação humana, os homens de ciência acreditam que os literatos são anti-intelectuais, ansiosos para restringir tanto a arte como o pensamento humano ao momento existencial (SNOW, 2015). Essa polaridade entre os saberes - ciências naturais versus humanidades - acaba se tornando uma das responsáveis por muitos dos estereótipos construídos em torno da imagem do cientista (e também dos literatos). Uma situação que Ian McEwan sabe explorar muito bem ao permitir que se tenha - pelo uso do discurso indireto livre - um acesso sem censura aos pensamentos de Michael Beard: "nenhum terceiranista de arte, por mais brilhante que fosse, seria capaz de se fazer passar por entendido, após uma semana de estudo, entre seus colegas matemáticos e físicos. Era uma rua de mão única" (MCEWAN, 2010, p. 242-243).

Ian McEwan criou um personagem que parece vir direto de uma comédia de erros. Contudo, ao lado de suas inúmeras trapalhadas, o autor vai alinhando uma série de características que desqualifica Michael Beard, não só como cientista, mas, principalmente, como homem. Diante dos olhos do leitor, o ganhador do Prêmio Nobel de Física transforma-se em um indivíduo desprezível, preocupado apenas com questões que possam atrair mais prestígio, dinheiro e poder. Os estereótipos ressaltam os preconceitos e as dificuldades de diálogo entre o personagem e outras áreas do saber, e a admiração por figuras proeminentes da ciência ajuda a compor um suposto ideal de cientista que há algum tempo não existe mais. A arrogância do personagem é a arrogância de todo aquele que acredita que o conhecimento é propriedade de uma elite ilustrada. Michael Beard reflete, com todas as suas idiossincrasias, o pensamento do homem moderno, seja ele um cientista ou um humanista.

\section{REFERÊNCIAS BIBLIOGRÁFICAS}

BHABHA, Homi K. O local da cultura. Trad. Myriam Ávila, Eliana Lourenço de Lima Reis, Gláucia Renate Gonçalves. Belo Horizonte: UFMG, 1998.

BAKHTIN, Mikhail. Problemas da poética de Dostoiévski. Trad. Paulo Bezerra. Rio de Janeiro: Forense-Universitária, 1981.

BARTHES, Roland. O praz̧er do texto. 6. ed. Trad. J. Guinsburg. São Paulo: Perspectiva, 2013.

BAKHTIN, Mikhail. Estética da criação verbal. Trad. feita a partir do francês por Maria Ermantina Galvão G. Pereira; revisão da tradução de Marina Appenzeller. São Paulo: Martins Fontes, 1997.

BOURDIEU, Pierre. Os usos sociais da ciência: por uma sociologia clínica do campo científico. Trad. Denice Barbara Catani. São Paulo: UNESP, 2004.

BRAIT, Beth. A personagem. São Paulo: Ática, 1985.

CALVINO, Italo. Assunto encerrado: discursos sobre literatura e sociedade. Trad. Roberta Barni. São Paulo: Companhia das letras, 2006. 
CANDIDO, Antonio et al. A personagem de ficção. 13ª ed. São Paulo: Perspectiva, 2014.

COMPAGNON, Antoine. O demônio da teoria: literatura e senso comum. Trad. Cleonice Paes Barreto Mourão e Consuleo Fortes Santiago. 2. Ed. Belo Horizonte: Editora UFMG, 2010.

CUNHA, M. B.; GIORDAN, M. A imagem da ciência no cinema. Química Nova na Escola. São Paulo: v. 31, n. 1, p. 9-17, 2009.

DAFLON, Cláudia. Literatos e cientistas. Disponível em:

<http://www.abralic.org.br/download/anaiseventos/cong2008/AnaisOnline/simposios/p df/009/CLAUDETE_DAFLON.pdf> Acesso em: 05 maio de 2015.

GALLEGO-TORRES, A. P. Imagen popular de la ciencia transmitida por los cómics. Revista Eureka sobre Enseñanza y Divulgación de las Ciencias, v. 4, n. 1, p. 141-151, 2007.

HAYNES, Roslynn. From faust to strangelove: representations of the scientist in western literature. Baltimore: Johns Hopkins University Press, 1994.

HÜLSENDEGER, Margarete J. V. C. A representação do físico na obra Solar, de Ian Mcewan. 2016. 109 f. Dissertação (Mestrado em Teoria da Literatura) - Pontifícia Universidade Católica do Rio Grande do Sul, Porto Alegre, 2016.

KOSMINSKY, L; GIORDAN, M. Visões de ciências e sobre cientista entre estudantes do ensino médio. Quimica Nova na Escola. São Paulo: v. 15, s/n, p. 11-18, 2002.

MCEWAN, Ian. Solar. Trad. Jorio Dauster. São Paulo: Companhia das Letras, 2010.

OLIVEIRA, Bernardo Jefferson de. Cinema e imaginário científico. História, Ciências, Saúde. Manguinhos: v. 13 (suplemento), p. 133-150, outubro 2006.

PAMUK, Orhan. O romancista ingênuo e o sentimental. Trad. Hildegard Feist. São Paulo: Companhia das Letras, 2011.

PEREIRA, M. E. Psicologia social dos estereótipos. São Paulo: EPU, 2002.

SAGAN, Carl. O mundo assombrado pelos demônios: a ciência vista como uma vela no escuro. Trad. de Rosaura Eichemberg. São Paulo: Companhia das Letras, 2006.

SNOW, C. P. As duas culturas e uma segunda leitura. 1. ed., 1. reimpr. Trad. de Geraldo Gerson de Souza, Renato de Azevedo Rezende Neto. São Paulo: Edusp, 2015.

Submetido em 30/01/2020 Aceito em 23/05/2020 